\title{
Cannabinoids Prevent the Effects of a Footshock Followed by Situational Reminders on Emotional Processing
}

\author{
Nachshon Korem' and Irit Akirav*,' \\ 'Department of Psychology, University of Haifa, Haifa, Israel
}

\begin{abstract}
Posttraumatic stress disorder (PTSD) can develop following exposure to a traumatic event. Hence, what we do in the first few hours after trauma exposure may alter the trajectory of PTSD. We examined whether cannabinoids can prevent the effects of a single footshock followed by situational reminders (SRs) on emotional processing. Rats were exposed to a footshock ( $1.5 \mathrm{~mA}$, $10 \mathrm{~s})$ on day I followed by exposure to SRs of the shock on days 3 and 5 . The CBI/2 receptor agonist WIN55,2I2-2 or vehicle were injected intraperitoneally $2 \mathrm{~h}$ after the shock. After I week, PTSD-like symptoms were examined. Exposure to SRs exacerbated the effects of the shock as rats exposed to shock and SRs, but not shock alone, showed impaired extinction of the traumatic event, impaired plasticity in the hippocmapal-accumbens pathway, enhanced latency to startle, and altered expression of CBI receptors (CBIr) and glucocorticoid receptors (GRs) in the CAI, basolateral amygdala (BLA) and prefrontal cortex (PFC). WIN55,2I2-2 prevented the effects of the shock and SRs on extinction, plasticity, and startle response. WIN55,2 I2-2 normalized the shock/SR-induced upregulation in CBI $r$ in the PFC, and CAI and GRs in the CAI, with no effect on BLA downregulation of CBIr and GRs. Shock and SRs caused lasting (I week) alterations in emotional processing associated with changes in GR and CBIr expression in brain areas related to PTSD. WIN55,2I2-2 administered after trauma exposure prevented these alterations via PFC- and CAI-CBIr and CAI-GRs.

Neuropsychopharmacology (20I4) 39, 2709-2722; doi: I0.1038/npp.20I4.132; published online 2 July 2014
\end{abstract}

\section{INTRODUCTION}

Posttraumatic stress disorder (PTSD) is an anxiety disorder that can develop following exposure to traumatic life events. PTSD is different from other psychiatric disorders, in that it has a very clear point of onset. Hence, what we do in the first few hours after trauma exposure may alter the trajectory of PTSD (Zohar et al, 2011).

The endocannabinoid system consists of cannabinoid receptors (CB1 and $\mathrm{CB} 2$ ), their endogenous lipid ligands, and the enzymatic machinery for endocannabinoid synthesis and degradation (Kogan and Mechoulam, 2006).

Recent clinical and preclinical evidence suggests that this system is a therapeutic target for the treatment of stress- and anxiety-related disorders such as PTSD (Marsicano et al, 2002; Fraser, 2009; Ganon-Elazar and Akirav, 2009, 2012, 2013; Moreira and Wotjak, 2010). We found a relatively broad therapeutic time window in the aftermath of trauma exposure for preventive treatment with cannabinoids. Rats were exposed to the single-prolonged stress (SPS) model of PTSD (restraint, forced swim, and sedation), and after an undisturbed period of 7 days, rats showed impaired extinction, enhanced acoustic startle response (ASR), and

*Correspondence: Dr I Akirav, Department of Psychology, University of Haifa, Mount Carmel, Haifa 31905, Israel, Tel: +972 48288268 , Fax: +972 4 8263157, E-mail: irit.akirav@gmail.com

Received 13 February 2014; revised 6 May 2014; accepted 30 May 20I4; accepted article preview online 5 June 2014 exaggerated negative feedback on the hypothalamicpituitary-adrenal (HPA) axis (Ganon-Elazar and Akirav, 2012). The CB1/2 receptor agonist WIN55,212-2 (0.5 mg/kg) administered intraperitoneally (i.p.) 2 or $24 \mathrm{~h}$ after SPS prevented the trauma-induced alterations in extinction, ASR potentiation, and HPA axis inhibition.

However, it has become increasingly clear that the consequences of exposure to trauma are affected not only by aspects of the event itself, but also by the frequency and severity of trauma reminders. Places and situations are the most frequent trauma reminders (Pynoos et al, 1996; Louvart et al, 2005; Corral-Frias et al, 2013). Hence, in this study, rats were placed in the light side of the light-dark apparatus and once entering the dark side, they received a single inescapable footshock (day 1), followed by two short reexposures to the light side (situational reminders (SRs)) on days 3 and 5 (Pynoos et al, 1996; Louvart et al, 2005; Corral-Frias et al, 2013). We aimed to assess the effects of posttrauma exposure on SRs and to examine whether cannabinoid receptor activation $2 \mathrm{~h}$ after exposure to trauma would prevent the effects of the shock and SRs on PTSD-like behavioral, physiological, and biochemical measures.

Impaired extinction of fear memories is thought to contribute to the development and persistence of the unrelenting memories of the trauma and to one of the hallmark symptoms in PTSD, that is, avoidance (Milad et al, 2007; Sripada et al, 2013). The exposure to trauma and SR model allows measuring avoidance behavior directed at the 
context of the trauma as well as the extinction of the traumatic event itself, and not the extinction of conditioned fear that is not directly associated with the traumatic event, as was previously studied in humans and animal models (Milad et al, 2007; Milad et al, 2008; Ganon-Elazar and Akirav, 2012, 2013; Sripada et al, 2013).

Maladaptive plasticity processes in response to specific external challenges are believed to underline disorders such as PTSD (Nathan et al, 2011). Growing attention has been focused on plasticity in the ventral subiculum (vSub)nucleus accumbens (NAc) pathway (O'Donnell and Grace, 1995; Abush and Akirav, 2010, 2013; Segev et al, 2013), as there is growing evidence for a role of the NAc in regulating mood and motivation (for review: Nestler and Carlezon, 2006), and in modulating fear-related behaviors after stress exposure that affects vSub and amygdala inputs to the NAc (Muschamp et al, 2011; Gill and Grace, 2013).

Finally, PTSD is associated with alterations in CB1 receptors (CB1r) and glucocorticoid receptors (GRs). Yehuda et al (2006) reported on a greater ACTH decline in response to hydrocortisone in PTSD patients, implying that central GRs are more responsive. Neumeister et al (2013) found that anandamide concentrations were reduced in PTSD patients relative to non-PTSD patients and suggested that abnormal CB1r-mediated anandamide signaling is implicated in the etiology of PTSD. Hence, we also measured the expression of CB1r and GRs in the fear circuit, which is considered dysfunctional in PTSD (that is, hippocampus, basolateral amygdala (BLA), and prefrontal cortex (PFC); Heim and Nemeroff, 2009) and in the NAc.

\section{MATERIALS AND METHODS}

\section{Subjects}

Male Sprague-Dawley rats (60 days old, $\sim 250 \mathrm{~g}$; Harlan, Jerusalem, Israel) were caged together at $22 \pm 2{ }^{\circ} \mathrm{C}$ under 12-h light/dark cycles (lights turned on at 07:00). Rats were allowed water and laboratory rodent chow ad libitum. The experiments were approved by the University of Haifa Ethics and Animal Care Committee, and adequate measures were taken to minimize pain or discomfort.

\section{Drug Treatment}

WIN55,212-2 (WIN; $0.5 \mathrm{mg} / \mathrm{kg}$ ) and the CB1 receptor antagonist AM251 (0.3 mg/kg; Cayman Chemicals) were dissolved in $1 \%$ dimethylsulfoxide (DMSO), $1 \%$ Tween-80, and $98 \%$ saline. Controls were given the vehicle (Veh) only. The selective serotonin reuptake inhibitor (SSRI) sertraline hydrochloride (SH; $10 \mathrm{mg} / \mathrm{kg}$; Toronto research chemicals) was dissolved in 5\% DMSO, 5\% Tween-80, and 90\% saline freshly every day. Drugs (vehicle, WIN, AM251, or SH1) were injected i.p. $2 \mathrm{~h}$ after the shock. An additional group was injected with SH once daily for 7 days (SH7; Matar et al, 2006).

\section{Trauma and SRs}

Animals were placed in an inhibitory avoidance apparatus $(50 \mathrm{~cm} \times 25 \mathrm{~cm} \times 30 \mathrm{~cm})$, divided into two equal-size compartments, and separated by an automatic guillotine door.
Except for the sensory-motor sequence tests, every rat underwent one behavioral or electrophysiological test to prevent carryover effects due to multiple behavioral tests.

Shock. On day 1, each rat was placed in the light compartment and after 2 min of exploration, the door was raised allowing access to the dark compartment. Thirty seconds after the rat entered the dark compartment, the door closed and the rat received an inescapable $1.5 \mathrm{~mA}$ shock for $10 \mathrm{~s}$. The rat remained in the dark side for an additional $20 \mathrm{~s}$, after which it was returned to the home cage. The no-shock groups received the same treatment, but with the shock mechanism inactivated.

SRs. Rats were placed in the light compartment on days 3 and 5 for 1 min with the gate closed to prevent them from entering the shock compartment (to avoid extinction).

Avoidance and extinction. On day 8, rats were submitted to a non-reinforced test trial every $24 \mathrm{~h}$ for 4 days (extinction 1-extinction 4). Each rat was placed in the light side of the box, and the time elapsed until it crossed over to the dark side (that is, latency) was measured. If, after $300 \mathrm{~s}$, the rat did not cross over on its own, the experimenter gently guided it to the dark side. The opening between the two sides of the shuttle was then blocked and the rat was allowed to freely explore the dark side for $180 \mathrm{~s}$, after which it was removed back to the home cage.

\section{Elevated Platform}

A different set of rats were placed on an elevated platform (EP; $11 \mathrm{~cm} \times 11 \mathrm{~cm}) 80 \mathrm{~cm}$ above the ground for $30 \mathrm{~min}$ in a brightly lighted room on days 3 and 5 . This procedure elicits stress responses in the form of behavioral 'freezing', defecation, and urination, and impairs extinction (Maroun and Akirav, 2008; Ganon-Elazar and Akirav, 2009).

\section{Electrophysiology}

Electrophysiology was as described in Abush and Akirav (2013) and Segev et al (2013). Briefly, rats were anesthetized ( $40 \%$ urethane, $5 \%$ chloral hydrate in saline; $4 \mathrm{ml} / 1 \mathrm{~kg}$, i.p.) and placed in a stereotaxic frame. A recording microelectrode was inserted into the NAc shell (anteroposterior, $+1.6 \mathrm{~mm}$; lateral, $\pm 1.0 \mathrm{~mm}$; ventral, $-5.5 \mathrm{~mm}$ ) and a bipolar $125 \mu \mathrm{m}$ stimulating electrode into the vSub (anteroposterior, $-6.5 \mathrm{~mm}$; lateral, $\pm 5.0 \mathrm{~mm}$; ventral, $-6.0 \mathrm{~mm}$ ). Evoked field potentials (EFPs) were digitized $(10 \mathrm{kHz})$ and analyzed using Cambridge Electronic Design (Cambridge, UK). Offline measurements were made of the amplitude and slope of the EFPs using averages of 30 successive responses to a given stimulation intensity applied at $0.1 \mathrm{~Hz}$. Test stimuli (monopolar pulses, $100 \mu$ s duration) were delivered at $0.1 \mathrm{~Hz}$. After positioning the electrodes, the rats were left for $1 \mathrm{~h}$ before commencing the experiment.

LTP was induced by high-frequency stimulation (HFS; three sets of 10 trains; each train consisting of 10 pulses at $200 \mathrm{~Hz}$; inter-train interval, $200 \mathrm{~ms}$; inter-set interval, $1 \mathrm{~min}$ ) to the vSub. 


\section{Acoustic Startle Response}

Rats were placed in $8 \times 8 \times 16 \mathrm{~cm}$ open animal holder that restricted locomotion but did not immobilize the animal (Coulbourn Instruments). Chambers were calibrated for both sensitivity to movement and sound level to ensure consistency between chambers and experiments. The animals were placed in the holder and allowed a 5-min acclimatization period with background noise only. Following the 5-min acclimatization period, 30 acoustic startle trials (120 dB white noise; $50 \mathrm{~ms}$ duration; $20-40 \mathrm{~s}$ intertrial interval) were presented over the $68 \mathrm{~dB}$ white noise background. Three measures of behavior were assessed: (1) mean startle amplitude; (2) mean latency to reach peak; and (3) an habituation index (a block of the last five responses/ a block of the first five responses).

\section{Sensory-Motor and Anxiety Tests}

Sensory-Motor and Anxiety Tests were as described in Abush and Akirav (2010). Briefly, rats were placed in a darkened open field (OF; $40 \times 40 \times 40 \mathrm{~cm}$ ) for $5 \mathrm{~min}$. After $24 \mathrm{~h}$, rats were placed in the elevated plus maze (EPM) for $5 \mathrm{~min}$. The EPM consisted of four arms $(55 \mathrm{~cm}$ each) on a stand $80 \mathrm{~cm}$ high. Data for the OF and EPM were analyzed using the behavioral tracking system Ethovision $\times \mathrm{T} 8.5$ (Noldus). After $24 \mathrm{~h}$, pain sensitivity (PS) was assessed by applying continuously ascending mild electric footshock (beginning at $0.0 \mathrm{~mA}$ and ending as soon as the animal flinched or vocalized). Two observers scored flinch and vocalization thresholds.

\section{Western Blotting}

Rats were killed and brain tissues of the infralimbic PFC, NAc shell, BLA, and CA1 were collected and homogenized in buffer. We concentrated on the IL-PFC as previous studies suggested the IL as involved in the enhancement of extinction learning (Milad and Quirk, 2002; Mueller et al, 2008).

Protein levels were determined by the bicinchoninic acid Protein Assay Kit (Pierce) according to the manufacturer's protocol. The samples were then diluted in SDS sample buffer, boiled $\left(100^{\circ} \mathrm{C}\right)$ for $5 \mathrm{~min}$, and stored at $-80^{\circ} \mathrm{C}$. Aliquots were subjected to SDS-PAGE (10\% polyacrylamide) and immunoblot analysis. Blots were incubated with the GR/CB1 antibody overnight at $4{ }^{\circ} \mathrm{C}(1: 100$, Pierce Antibodies), followed by washing and $1 \mathrm{~h}$ incubation with an HRP-linked secondary antibody at room temperature (goat anti-rabbit IgG; Jackson ImmunoResearch Laboratories, 1:10000). Blots were visualized by enhanced chemiluminescence with ECL (Biological Industries) and quantified with an XRS charge-coupled device camera (BioRad Laboratories) and Quantity One software. All protein samples were standardized with $\beta$-actin $(1: 5000$, polyclonal goat antibody; Santa Cruz Biotechnology, USA).

\section{Statistical Analysis}

The results are expressed as means \pm SEM. For statistical analysis, one-way ANOVA, two-way ANOVA, mixed design three-way ANOVA, and one-sample $t$-test were used as indicated. All post hoc comparisons were made using the least significant difference multiple-comparison test.

\section{RESULTS}

\section{WIN55,212-2 Prevents the Effects of Shock and SRs on Extinction}

Mixed design three-way ANOVA (shock $\times$ SR $\times$ extinction day $(2 \times 2 \times 4))$ on the latency to enter the dark side indicated a significant effect for shock $\left(\mathrm{F}_{(1,35)}=57.43\right.$, $p<0.001$; Figure 1a), day $\left(\mathrm{F}_{(3,105)}=16.51, p<0.001\right)$, and the following interactions: shock $\times \mathrm{SR} \quad\left(\mathrm{F}_{(1,35)}=4.28\right.$, $p<0.05)$, day $\times$ shock $\left(\mathrm{F}_{(3,105)}=11.86, p<0.001\right)$, day $\times \mathrm{SR}$ $\left(\mathrm{F}_{(3,105)}=6.59, p<0.001\right)$, and day $\times$ shock $\times \mathrm{SR}\left(\mathrm{F}_{(3,105)}=\right.$ 5.51, $p<0.001)$.

Post hoc comparison revealed that on extinction 1, the shock groups demonstrated increased latency compared with no-shock groups $(p<0.001)$ and the shock-no SR group demonstrated increased latency compared with the shock-SR group $(p<0.05)$. On extinction $2-4$, the shock-SR group demonstrated increased latency compared with all groups (no shock-no SR: extinction 2: $p<0.01$, extinction 3-4: $p<0.001$; no shock-SR: $p<0.001$; shock-no SR: extinction 2-3: $p<0.05$, extinction 4: $p<0.001)$. Hence, the shock groups avoided the dark side (extinction 1), but only the shock-SR group demonstrated impaired extinction kinetics.

Next, we examined whether WIN55,212-2 can prevent the effects of trauma and SRs on extinction. A mixed design three-way ANOVA $(\mathrm{SR} \times$ drug $\times$ extinction day $(2 \times 2 \times 4))$ indicated significant effects for SRs $\left(\mathrm{F}_{(1,34)}=9.24, p<0.01\right)$, drug $\left(\mathrm{F}_{(1,34)}=15.65, p<0.001\right)$, and day $\left(\mathrm{F}_{(3,102)}=17.27\right.$, $p<0.001$; Figure 1b) with no significant interactions. Although the interactions were not significant, there was an important effect for drug. Hence, we continued with oneway ANOVA and post hoc comparisons on each extinction day. Post hoc comparison revealed that on extinction 2, the shock-SR Veh group showed increased latency compared with the shock-no SR WIN group $(p<0.05)$. On extinction 3-4, the shock-SR Veh group showed increased latency compared with all groups (extinction 3: no SR groups: $p<0.01$, shock-SR WIN: $p<0.001$; extinction 4: no SR groups: $p<0.001$, shock-SR WIN: $p<0.05)$. Hence, WIN55,212-2 prevented the effects of shock and SRs on extinction.

As WIN55,212-2 is a CB1/CB2 agonist, we examined whether the preventing effects of WIN55,212-2 on extinction are mediated by the CB1 receptor. A mixed design twoway ANOVA (group $\times$ extinction day $(4 \times 4)$ ) on the latency to enter the dark side did not reveal significant effects (Figure 1c). Hence, injecting a low dose of AM251 after the shock had no effect on extinction. AM251 partially prevented the effects of WIN55,212-2 on extinction as there was no significant increase in the latency from extinction 1 to extinction 4 in the shock-SR WIN + AM251 group.

To further validate our model, we added two control expeiments. In the first experiment, rats were exposed to the shock, and on days 3 and 5, were exposed to an out-ofcontext stressor (that is, the EP stress). These rats (shockEP) were compared with shocked rats that were exposed to SRs (shock-SR) or not (shock-no SR). A mixed design two-way ANOVA (group $\times$ extinction day $(3 \times 4))$ on the 

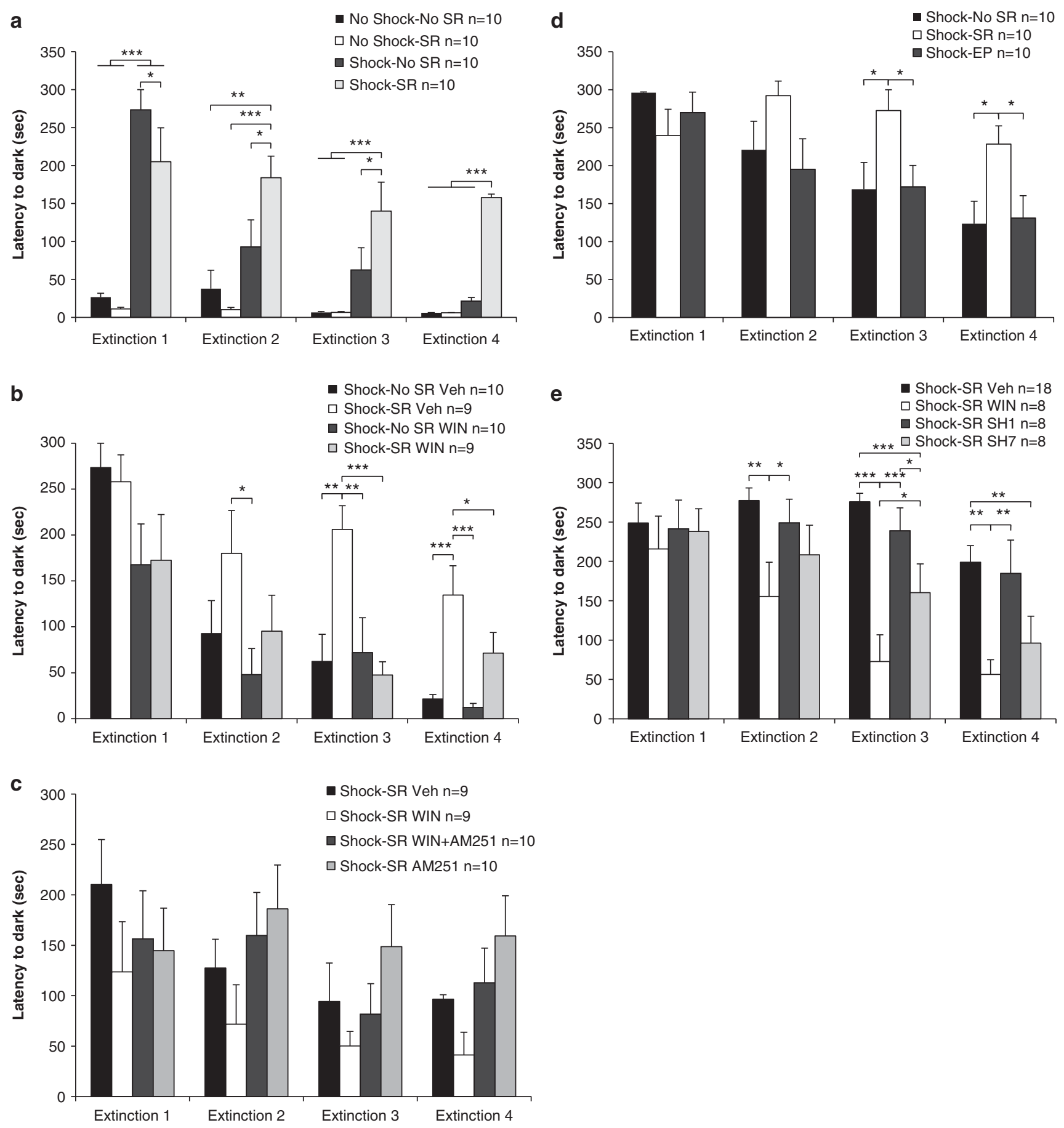

Figure I WIN55,2I2-2 prevents the effects of shock and SRs on extinction (Ext). (a) On Ext I, the shock groups (shock-no SR, shock-SR) demonstrated increased latency compared with the no-shock groups. On Ext2-4, the shock-SR group demonstrated increased latency compared with all groups $\left(* p<0.05\right.$; ${ }^{*} p<<0.01$; *** $p<0.00$ I). (b) When WIN55,2I2-2 was injected $2 \mathrm{~h}$ after the shock, the shock-SR Veh group showed increased latency compared with the shock-no SR WIN group on Ext2. On Ext3 and 4, the shock-SR Veh group showed increased latency compared with all groups $(* p<0.05$; *** $<0.0$ I; **** $p<0.00$ I). (c) When the antagonist AM25I was injected, no significant differences were observed between the groups. (d) The shock-SR group demonstrated increased latency to enter the dark side on Ext3 and 4, compared with the shock-no SR group and with rats exposed to shock and placed on the EP on days 3 and 5 after the shock (shock-EP; * $<0.05)$. (e) Rats were injected with sertraline once (shock-SR SHI) or once daily for 7 days (shock-SR SH7). The shock-SR WIN group demonstrated reduced latency compared with the shock-SR Veh and shock-SR SHI groups on Ext2, Ext3, and Ext 4. On Ext3, the WIN group also demonstrated increased latency compared with the SH7 group. The SH7 group demonstrated reduced latency compared with the Veh $(p<0.00 \mathrm{I})$ and $\mathrm{SHI}(p<0.05)$ groups on Ext3 and compared with the Veh group on Ext4 (*p<0.05; *** $<<0.0 \mathrm{I}$; ***** $p<0.001)$.

latency to enter the dark side revealed a significant effect for group $\left(\mathrm{F}_{(1,27)}=3.99, p<0.05\right.$; Figure $\left.1 \mathrm{~d}\right)$, day $\left(\mathrm{F}_{(3,81)}=9.56\right.$, $p<0.001)$, and a significant day $\times$ group interaction
$\left(\mathrm{F}_{(6,105)}=2.58, p<0.05\right)$. Post hoc comparison revealed that on extinction days 3 and 4, the shock-SR group demonstrated increased latency compared with all groups 
$(p<0.05)$. Hence, the shock-EP group demonstrated the same extinction kinetics as the shock-no SR group.

In the second control experiment, we tested whether a classic SSRI can prevent the effects of shock and reminders on extinction. Rats were exposed to the shock and injected with SH, which was previously shown to reduce PTSD-like symptoms in rats when injected for 7 days starting after the trauma (Matar et al, 2006). Repeated measures ANOVA $($ drug $\times$ extinction day $(4 \times 4))$ revealed a significant effect for drug $\left(\mathrm{F}_{(3,38)}=7.43, p<0.001\right)$, day $\left(\mathrm{F}_{(3,114)}=14.77\right.$, $p<0.001)$, and a day $\times$ drug interaction $\left(\mathrm{F}_{(9,114)}=2.17\right.$, $p<0.05$; Figure 1e). Post hoc comparison revealed that on extinction day 2, shock-SR WIN showed reduced latency compared with the shock-SR Veh $(p<0.01)$ and shock-SR SH1 ( $p<0.05$; injected once with SH) groups. On extinction 3 , the shock-SR WIN group showed reduced latency compared with all groups (shock-SR Veh SH1: $p<0.001$; shock-SR SH7: $p<0.05$ ). The shock-SR SH7 group (injected for 7 days) showed reduced latency compared with the shock-SR Veh $(p<0.001)$ and shock-SR SH1 $(p<0.05)$ groups. On extinction 4 , the shock-SR WIN group showed reduced latency compared with the shock-SR Veh and SH1 groups $(p<0.01)$. The shock-SR SH7 group showed reduced latency compared with the shock-SR Veh group $(p<0.01)$. Hence, treating rats with SH for 7 days after the trauma facilitated extinction compared with vehicle-treated rats. Nonetheless, the effects of SH were not as robust as the effects of WIN55,212-2 on extinction. The acute SSRI treatment had no effect on extinction.

Repeated measures ANOVA (treatment $\times$ extinction day $(2 \times 4))$ did not reveal differences between the vehicletreated rats ( 1 vehicle $v s 7$ vehicle injections; $\mathrm{F}_{(1,16)}<1, \mathrm{NS}$ ), hence they were grouped together to a control group (shock-SR Veh, $n=18$ ).

\section{WIN55,212-2 Prevents the Effects of Shock and SRs on Synaptic Plasticity}

Post-HFS analysis using mixed design three-way ANOVA (shock $\times \mathrm{SR} \times$ time $(2 \times 2 \times 12))$ on EFPs' amplitude (Figure 2a) and slope (Figure 2b) levels indicated a significant main effect for shock (amplitude: $\mathrm{F}_{(1,28)}=9.78$, $p<0.01$; slope: $\mathrm{F}_{(1,28)}=11.69, p<0.01$ ) and SR (amplitude: $\mathrm{F}_{(1,28)}=4.78, p<0.05$; slope: $\left.\mathrm{F}_{(1,28)}=5.13, p<0.05\right)$. Post hoc analysis revealed a significant difference between the shock-SR group and the other groups $(p<0.01)$. Hence, exposure to shock and SRs impaired LTP. Mixed design three-way ANOVA on amplitude and slope pre-HFS (drug $\times$ stress $\times$ time $(2 \times 2 \times 5))$ did not reveal any significant effects.

To examine the effects of shock and SRs on baseline synaptic activity, input-output measurements were taken. Analysis revealed a significant effect for stimulation intensity $\left(\mathrm{F}_{(1,28)}=134.15, p<0.001\right)$. Stimulation of the vSub input into the NAc with different stimulus intensities did not result in any other significant effects on basal EFPs (Figure 2c).

When WIN55,212-2 was injected, post-HFS analysis using mixed design three-way ANOVA (drug $\times \mathrm{SR} \times$ time $(2 \times 2 \times 12))$ on EFPs' amplitude (Figure $2 \mathrm{~d}$ ) and slope (Figure 2e) indicated a significant main effect for shock (amplitude: $\mathrm{F}_{(1,25)}=5.37, p<0.05$; slope: $\mathrm{F}_{(1,25)}=4.25$, $p<0.05$ ), SR (amplitude: $F_{(1,25)}=4.15, \quad p<0.05$; slope: $\left.\mathrm{F}_{(1,25)}=4.05, p<0.05\right)$, and drug $\times \mathrm{SR}$ interaction (amplitude: $\mathrm{F}_{(1,25)}=4.48, p<0.05$; slope: $\left.\mathrm{F}_{(1,25)}=4.68, p<0.05\right)$. Post hoc analysis revealed a significant difference between the shock-SR Veh group and the other groups $(p<0.01)$. Hence, WIN55,212-2 prevented the impairing effects of the shock and SRs on LTP.

To examine the effects of WIN55,212-2 on baseline synaptic activity, input-output measurements were taken. Mixed design three-way ANOVA on amplitude and slope pre-HFS (drug $\times \mathrm{SR} \times$ time $(2 \times 2 \times 5))$ did not reveal any significant effects. Analysis of input-output curve revealed a significant effect for stimulation intensity $\left(\mathrm{F}_{(1,25)}=104.51\right.$, $p<0.001$; Figure 2f).

When AM251 was injected, post-HFS analysis using mixed design ANOVA (group $\times$ time $(4 \times 12)$ ) on EFPs' amplitude (Figure $2 \mathrm{~g}$ ) and slope (Figure $2 \mathrm{~h}$ ) indicated a significant main effect for group (amplitude: $\mathrm{F}_{(3,24)}=11.46$, $p<0.001$; slope: $\left.\mathrm{F}_{(3,24)}=15.18, p<0.001\right)$. Post hoc analysis revealed a significant difference between the shock-SR WIN group and the other groups $(p<0.001)$. Hence, AM251 prevented the effects of WIN55,212-2 on LTP.

Mixed design three-way ANOVA on amplitude and slope pre-HFS (group $\times$ time $(2 \times 5)$ ) did not reveal any significant effects. Analysis of input-output curve revealed a significant effect for stimulation intensity $\left(\mathrm{F}_{(1,24)}=134.62\right.$, $p<0.001)$ and stimulation intensity $\times$ group interaction $\left(\mathrm{F}_{(3,24)}=3.33, p<0.05\right.$; Figure 2i).

\section{WIN55,212-2 Prevents the Effects of Shock and SRs on Startle Response}

Two-way ANOVA (shock $\times$ SR $(2 \times 2))$ on the latency to startle revealed a significant effect for SRs $\left(\mathrm{F}_{(1,37)}=12.69\right.$, $p<0.001)$ and shock $\times$ SR interaction $\left(\mathrm{F}_{(1,37)}=6.43, p<0.05\right.$; Figure 3a). Post hoc comparison revealed that the shock-SR group demonstrated a significant reduction in the latency to startle compared with all groups (no shock-no SR: $p<0.01$; no shock-SR: $p<0.05$; shock-no SR: $p<0.001$ ).

When WIN55,212-2 was injected, two-way ANOVA $($ drug $\times$ SR $(2 \times 2))$ revealed a significant effect for SRs $\left(\mathrm{F}_{(1,36)}=7.87, \quad p<0.01\right)$ and the interaction drug $\times \mathrm{SR}$ $\left(\mathrm{F}_{(1,36)}=12.07, p<0.001\right.$; Figure $\left.3 \mathrm{~b}\right)$. Post hoc comparison revealed that the shock-SR Veh group demonstrated a significant reduction in the latency to startle compared with all groups $(p<0.01)$. Hence, WIN55,212-2 prevented the shock/SR-induced decrease in the latency to startle.

When the antagonist AM251 was injected, one-way ANOVA revealed a significant effect for drug $\left(\mathrm{F}_{(3,36)}=\right.$ 8.76, $p<0.001)$. Post hoc comparison revealed that the shock-SR WIN group demonstrated increased latency to startle compared with all groups $(p<0.001$; Figure $3 c)$. Hence, AM251 prevented the effects of WIN55,212-2 on the latency to startle.

There were no effects on startle amplitude or the habituation index throughout the experiments, and no correlation was found between these measures and the latency to startle.

To further validate our model, a different set of rats were exposed to the shock, and on days 3 and 5, were exposed to an out-of-context stressor (that is, the EP stress). One-way ANOVA revealed a significant effect for group 


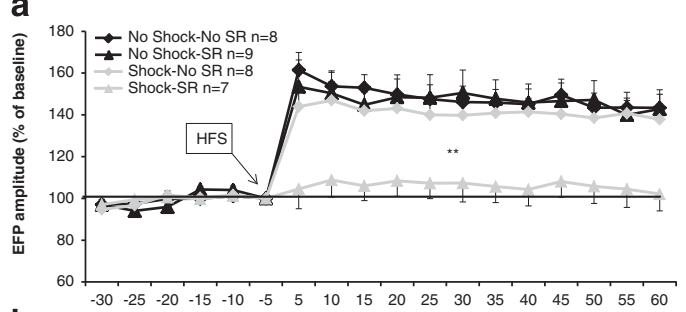

b

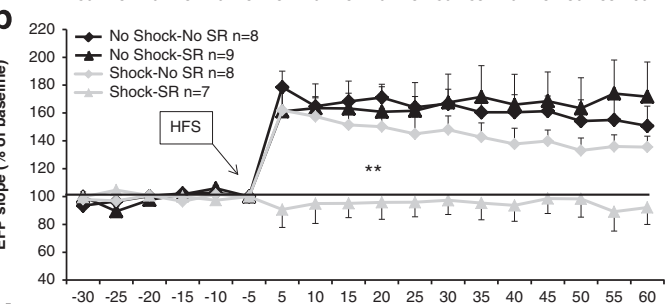

d

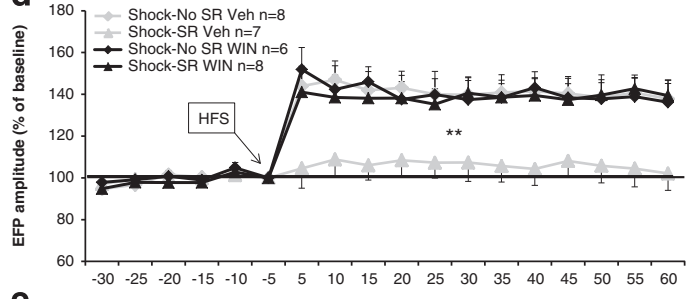

e

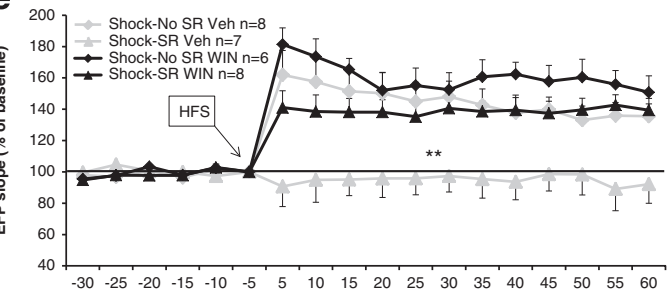

g Shock-SR Vehn $n=7$

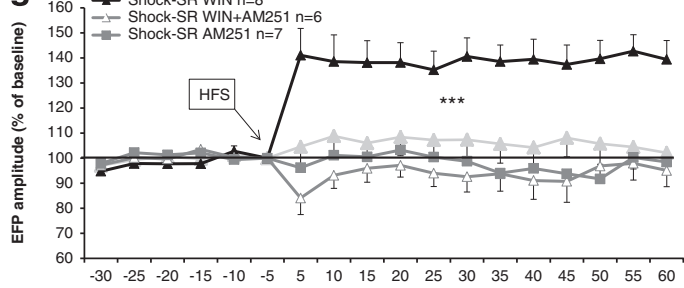

$\begin{array}{ll}h_{180} & \\ & \\ & \text { Shook-SR Veh } \mathrm{n}=7 \\ \text { Shock-SR WIN } \mathrm{n}=8\end{array}$

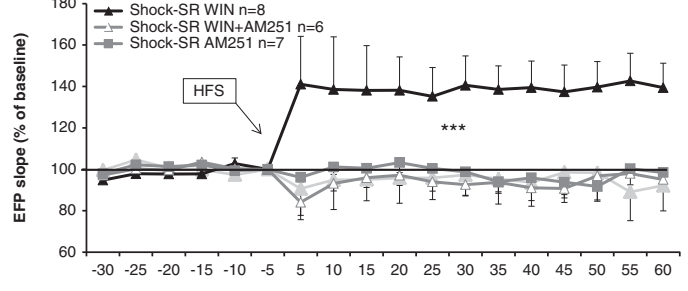

j

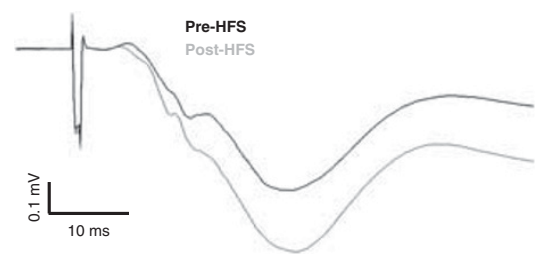

C
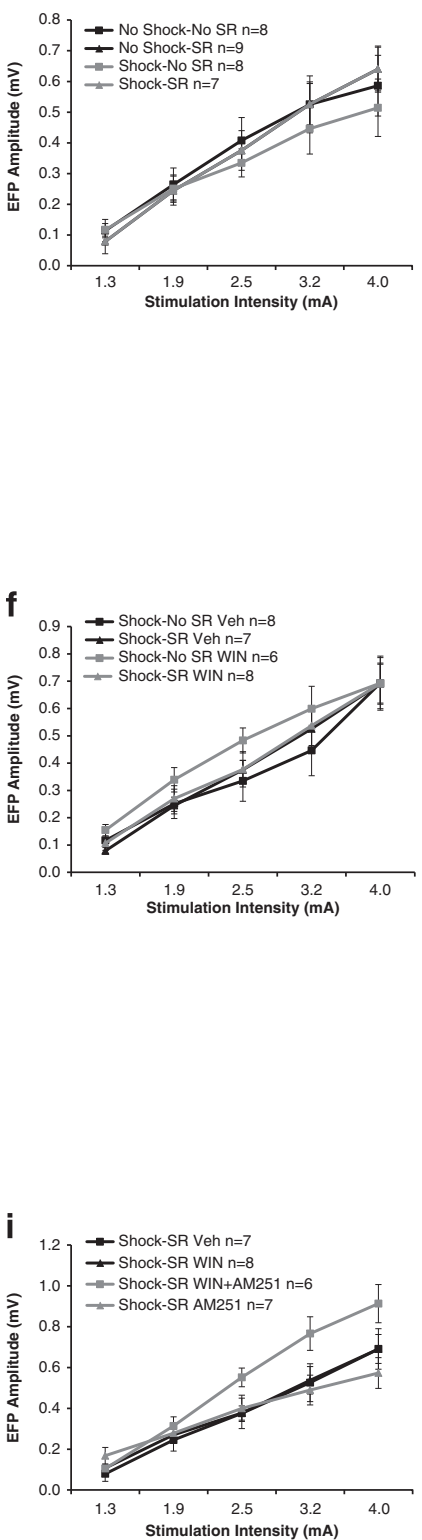

k
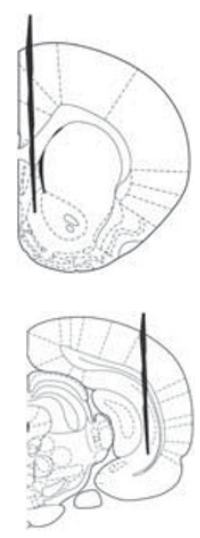
$\left(\mathrm{F}_{(2,27)}=3.94, p<0.05\right)$. Post hoc comparison revealed that the shock-SR group demonstrated increased latency to startle compared with all groups $(p<0.05$; Figure $3 \mathrm{~d})$. Hence, the latency to startle in the shock-EP group was similar to the latency observed in the shock-no SR group.

\section{The Effects of Trauma Exposure, SRs, and WIN55,212-2 on Anxiety and Sensory-Motor Measures}

In the OF (Table 1, experiment 1), two-way ANOVA $($ shock $\times$ SR $(2 \times 2))$ revealed a significant effect for shock on the total distance covered $\left(\mathrm{F}_{(1,35)}=39.15, p<0.001\right)$, freezing levels $\left(\mathrm{F}_{(1,35)}=20.17, p<0.001\right)$, and time in the center $\left(\mathrm{F}_{(1,35)}=22.45, \quad p<0.001\right)$. Post hoc comparison revealed that compared with the no-shock groups, the shock groups traveled less distance $(p<0.001)$, demonstrated increased freezing $(p<0.01)$, and avoided the center of the arena $(p<0.01)$.

When WIN55,212-2 was injected (Table 1, experiment 2), one-way ANOVA did not reveal a significant difference between the groups in the distance traveled, freezing levels, or time in the center. Hence, WIN55,212-2 did not prevent the shock/SR-induced increase in anxiety levels.

In the EPM (Table 1, experiment 1), two-way ANOVA $($ shock $\times$ SR $(2 \times 2))$ revealed a significant effect for shock on the total distance covered $\left(\mathrm{F}_{(1,36)}=13.98, p<0.001\right)$ and the percent of time the rats spent in the open arms $\left(\mathrm{F}_{(1,36)}=9.98, p<0.01\right)$. Post hoc comparison revealed that the shock groups traveled less distance than the no shockno SR group $(p<0.01)$, and the shock-no SR group traveled less than the no shock-SR group $(p<0.01)$. Further, the shock groups spent more time in the open arms than the no shock-no SR group $(p<0.01)$.

When WIN55,212-2 was injected (Table 1, experiment 2), one-way ANOVA did not reveal significant differences between the groups.

In the PS test (Table 1, experiment 1), two-way ANOVA $($ shock $\times$ SR $(2 \times 2))$ revealed a significant effect for shock in the PS threshold $\left(\mathrm{F}_{(1,37)}=31.41, p<0.001\right)$. Post hoc comparison revealed that the shock groups demonstrated higher threshold than the no shock-no SR $(p<0.001)$ and the no shock-SR $(p<0.01)$ groups.

When WIN55,212-2 was injected (Table 1, experiment 2), one-way ANOVA revealed a significant difference between the groups $\left(\mathrm{F}_{(3,37)}=6.45, p<0.001\right)$. Post hoc comparison revealed that the WIN-treated rats demonstrated lower threshold $(p<0.01)$ than the vehicle-treated rats. Hence,
WIN55,212-2 prevented the shock/SR-induced increase in PS threshold.

When AM251 was injected (data not shown), one-way ANOVA revealed a significant difference between the groups $\left(\mathrm{F}_{(3,35)}=3.88, \quad p<0.05\right)$. Post hoc comparison revealed that the shock-SR WIN group demonstrated lower threshold compared with all groups $(p<0.01)$. Hence, AM251 prevented the effects of WIN55,212-2 on PS threshold.

\section{The Effects of Trauma Exposure, SRs, and WIN55,212-2 on the Expressions of CB1r and GRs}

Finally, we aimed to examine whether the preventive effects of WIN55,212-2 after shock and SRs are mediated by CB1r and GR in the fear circuit.

CB1r and GR levels were analyzed using one-way ANOVA in all areas tested. To confirm equal protein loading, the same blots were re-hybridized with antibodies specific for $\beta$-actin. No significant difference in $\beta$-actin levels was observed between the groups in any of the brain areas tested, suggesting that $\beta$-actin levels were not affected by the treatment.

In the $I L-P F C$, a significant group effect was found for CB1r $\left(\mathrm{F}_{(2,27)}=4.62, p<0.05\right.$; Figure $\left.4 \mathrm{a}\right)$ but not for $\mathrm{GR}$ (Figure 4b). Post hoc comparison revealed that the shockSR Veh group expressed significantly more CB1r than all groups $(p<0.05)$.

In the $B L A$, a significant group effect was found for $\mathrm{CB} 1 \mathrm{r}$ $\left(\mathrm{F}_{(2,27)}=4.46, p<0.05\right.$; Figure $\left.4 \mathrm{~d}\right)$ and $\mathrm{GR}\left(\mathrm{F}_{(2,27)}=6.53\right.$, $p<0.01$; Figure $4 \mathrm{e})$. Post hoc comparison revealed that the no shock-no SR Veh group expressed more CB1r $(p<0.01$; $p<0.05)$ and GR $(p<0.05 ; p<0.01)$ than the shock-SR Veh and the shock-SR WIN groups, respectively.

In the CA1, a significant group effect was found for $\mathrm{CB} 1 \mathrm{r}$ $\left(\mathrm{F}_{(2,27)}=4.65, p<0.05\right.$; Figure $\left.4 \mathrm{~g}\right)$ and GRs $\left(\mathrm{F}_{(2,27)}=5.04\right.$, $p<0.05$; Figure $4 \mathrm{~h})$. Post hoc comparison revealed that the shock-SR Veh group expressed significantly more CB1r $(p<0.05)$ and GRs $(p<0.01)$ than all groups.

In the NAc, no significant differences were observed between the groups in CB1r (Figure 4j) and GR expression (Figure 4k).

We added a control experiment in which rats were injected with vehicle or WIN55,212-2 and 1 week later decapitated (with no shock or SRs). We found no differences in the expression of CB1r and GRs between the groups (PFC: CB1r $\left(\mathrm{t}_{(12)}=0.25, \mathrm{NS}\right), \mathrm{GR}\left(\mathrm{t}_{(12)}=0.1, \mathrm{NS}\right)$;

Figure 2 The effects of shock, SRs and WIN55,2I2-2 on LTP. (a) When tested on day 8, the shock-SR group demonstrated significantly reduced amplitude compared with all groups post-HFS $(* * *<0.0$ I). (b) When tested on day 8 , the shock-SR group demonstrated significantly reduced slope compared with all groups post-HFS (** $<0.0 \mathrm{I}$ ). (c) Input-output curve: no significant differences between the groups were found in NAc EFP amplitudes after stimulation of vSub input with different stimulus intensities. (d) When the agonist WIN55,2I 2-2 was injected, the shock-SR Veh group demonstrated significantly reduced amplitude compared with all groups post-HFS (** $<<0.01$ ). (e) When the agonist WIN55,2I2-2 was injected, the shock-SR Veh group demonstrated significantly reduced slope compared with all groups post-HFS (** $p<0.0 I$ ). ( $f$ ) Input-output curve: no significant differences between the groups were found in NAc EFP amplitudes after stimulation of vSub input with different stimulus intensities. (g) When the antagonist AM25I was injected, the shock-SR WIN group demonstrated significantly increased amplitude compared with all groups post-HFS (*** $<0.00 \mathrm{I})$. (h) When the antagonist AM25I was injected, the shock-SR WIN group demonstrated significantly increased slope compared with all groups post-HFS (**** $<0.00$ I). (i) Input-output curve: no significant differences between the groups were found in NAc EFP amplitudes after stimulation of vSub input with different stimulus intensities. (j) Representative signal trace in the NAc taken before and I h after HFS to the vSub. (k) Schematic of coronal sections of the rat brain representing the recording site in the nucleus accumbens shell (coordinates: $1.6 \mathrm{~mm}$ anterior, I mm lateral, and $5 \mathrm{~mm}$ ventral to bregma). (I) Schematic of coronal sections of the rat brain representing the stimulating site in the ventral subiculum (coordinates: $6.5 \mathrm{~mm}$ posterior, $5 \mathrm{~mm}$ lateral, and $6 \mathrm{~mm}$ ventral to bregma). 
a

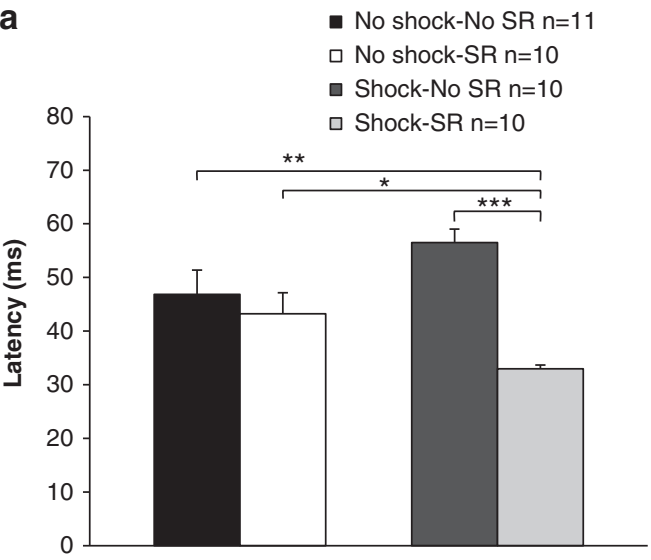

C

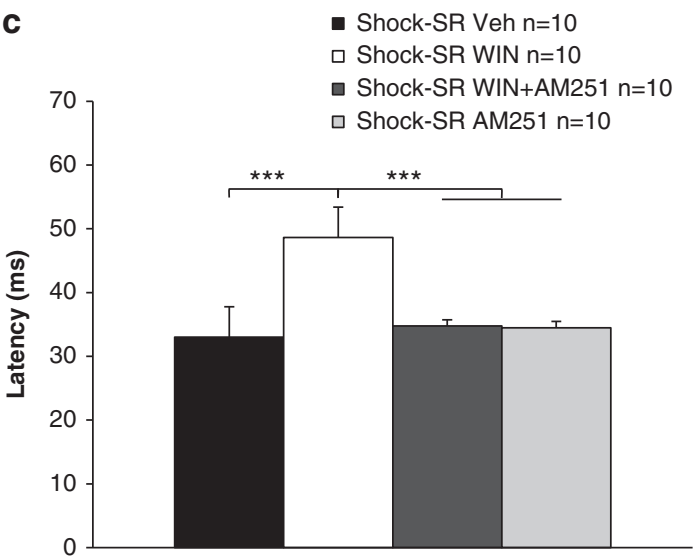

b

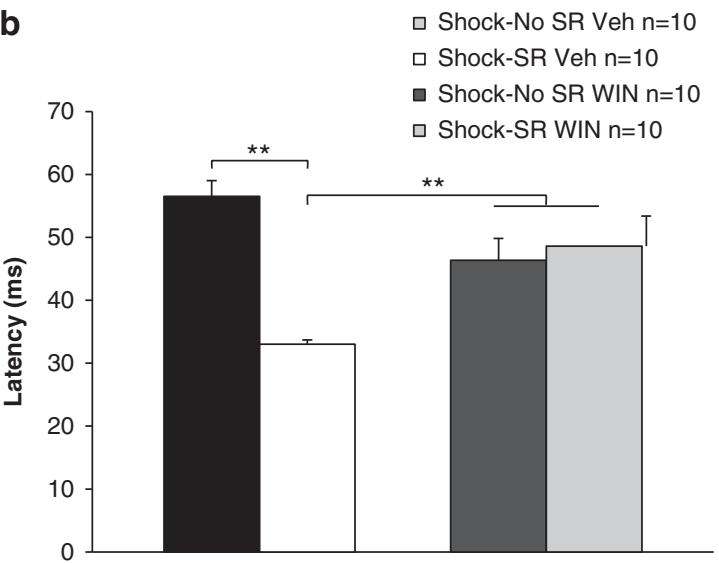

d

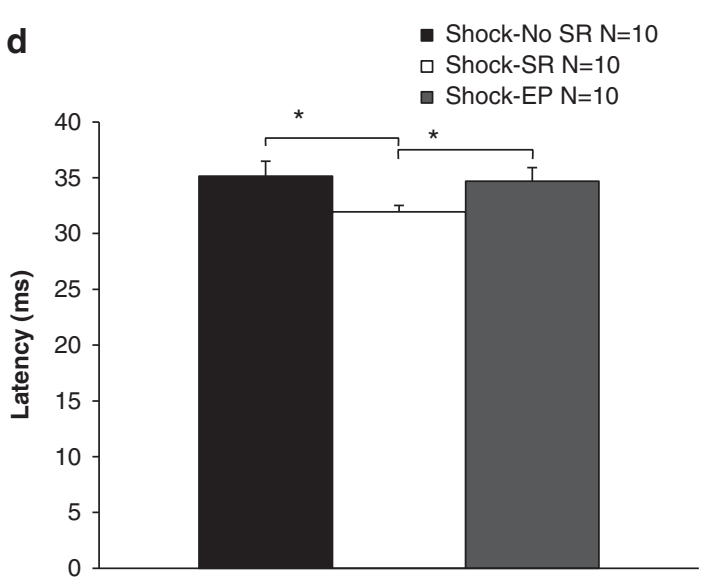

Figure 3 WIN55,2I2-2 prevents the effects of shock and SRs on startle response. (a) The shock-SR group demonstrated a significant reduction in the latency to startle compared with all groups (* $<<0.05$; ** $p<0.0$ I; **** $p<0.00 \mathrm{I}$ ). (b) When WIN55,2I2-2 was injected $2 \mathrm{~h}$ after the shock, the shock-SR Veh group demonstrated a significant reduction in the latency to startle compared with all groups (** $p<0.0 \mathrm{I}$ ). (c) When the antagonist AM25I was injected, the shock-SR WIN group demonstrated increased latency to startle compared with all groups (**** $<0.00 \mathrm{I}$ ). (d) The shock-SR group demonstrated increased latency to startle compared with the shock-no SR group and with rats exposed to shock and placed on the EP on days 3 and 5 after the shock (shock-EP) $\left({ }^{*} p<0.05\right)$.

BLA: CB1r $\left(\mathrm{t}_{(12)}=0.78\right.$, NS), GR $\left(\mathrm{t}_{(12)}=0.81, \mathrm{NS}\right)$; CA1: CB1r $\left(\mathrm{t}_{(12)}=0.53\right.$, NS), GR $\left(\mathrm{t}_{(12)}=0.82\right.$, NS); NAc: CB1r $\left.\left(\mathrm{t}_{(11)}=0.1, \mathrm{NS}\right), \mathrm{GR}\left(\mathrm{t}_{(12)}=0.81, \mathrm{NS}\right)\right)$.

\section{DISCUSSION}

Exposure to shock and SRs resulted in changes in emotional processing observed 1 week after the initial stress. Rats exposed to intense shock and SRs avoided the shock context and showed impaired extinction of the traumatic event, showed impaired plasticity in the vSub-NAc pathway, and enhanced latency to startle. Exposure to shock by itself was not sufficient to provoke all of these changes and rats exposed to shock (with or without the following exposure to SRs) demonstrated avoidance, increased anxiety, and hypoalgesia. This suggests that exposure to SRs exacerbated the effects of the shock on behavior and physiology. Rats exposed to shock and SRs also demonstrated alterations in the expression of CB1r and GRs in brain areas found to be dysfunctional in PTSD (that is, BLA, PFC, and CA1).
Notably, administering the cannabinoid agonist WIN55,212-2 $2 \mathrm{~h}$ after shock exposure prevented the effects of the shock and SRs on extinction, plasticity, startle response, and PS. These findings are particularly encouraging as the available drugs (for example, SSRIs and serotoninnorepinephrine reuptake inhibitors) provide some benefit in the management of PTSD symptoms, but effect sizes are small and in some cases ineffective (Stein et al, 2006).

The agonist WIN55,212-2 also prevented the shock/SRinduced upregulation in CB1r in the PFC and CA1 and upregulation in GRs in the CA1, suggesting that these receptors mediate the therapeutic effects of WIN55,212-2 on behavior and physiology. WIN55,212-2 did not prevent the shock/SR-induced downregulation of CB1r and GRs in the BLA.

In general, a low dose of the CB1 antagonist AM251 administered after the shock had no effect on behavior or plasticity by itself, but when co-administered with WIN55,212-2 it blocked the preventive effects of WIN55,212-2 administered after the shock on plasticity, startle response, and PS. Hence, the preventing effects of 
Table I The Effects of Shock, SRs and WIN55,2I2-2 on Sensory-Motor and Anxiety Tests

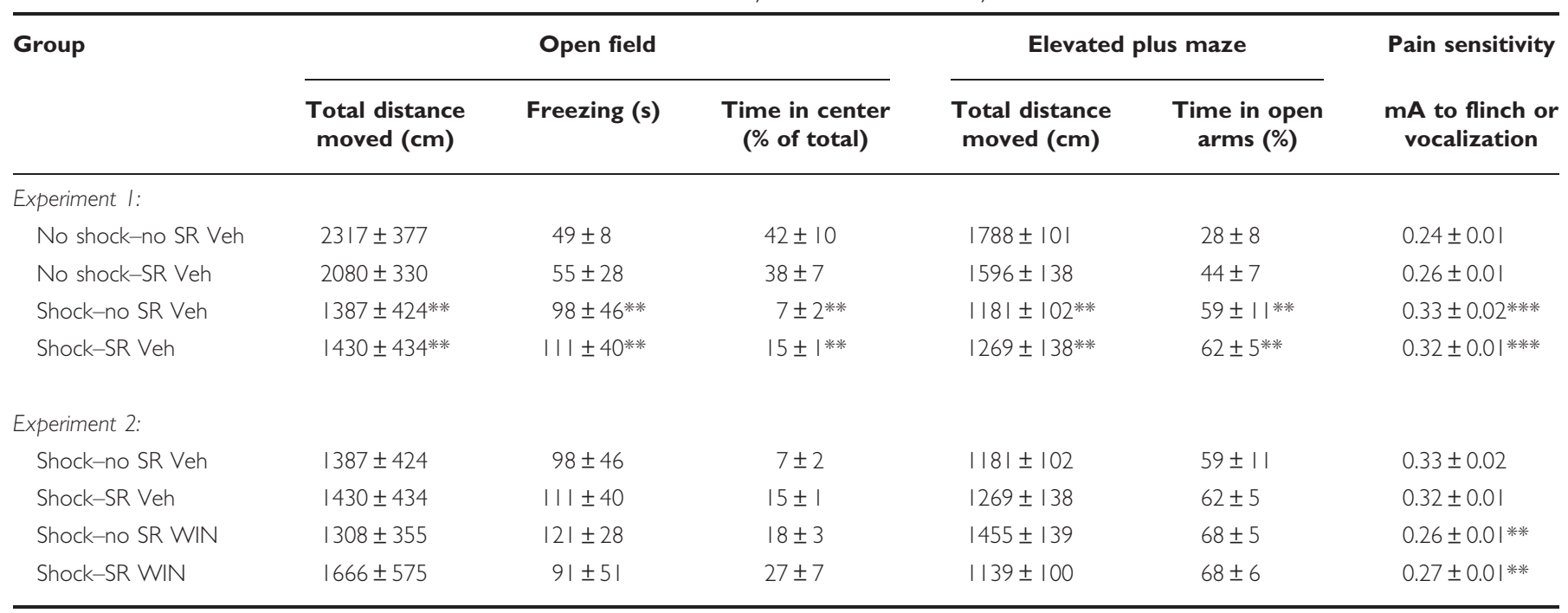

Abbreviation: SR, situational reminder.

In the OF (experiment I), the shock groups (shock-SR and shock-no SR) traveled less distance, spent more time freezing, and spent less time in the center than the no-shock groups (no shock-no SR and no shock-SR; ** $<<0.01$ ).

When WIN55,2 12-2 was injected (experiment 2), there was no significant difference between the groups in the distance traveled, freezing levels, or time in the center. In the EPM (experiment I), the shock groups (shock-SR and shock-no SR) traveled less distance and spent more time in the open arms than the no-shock groups (no shock-no SR and no shock-SR; *** $<<0.01$ ).

When WIN55,2 I2-2 was injected (experiment 2), there was no significant difference between the groups in the distance traveled or time spent in the open arms. In the PS test (experiment I), the shock groups (shock-SR and shock-no SR) were less sensitive to shock intensity than the no-shock groups (no shock-no SR and no shock-SR; ***** $p<0.001$ ).

When WIN55,2 I2-2 was injected (experiment 2), the WIN groups (shock-SR WIN and shock-no SR WIN) were more sensitive than the vehicle groups (shock-SR WIN and shock-no SR WIN; *** $p<0.01$ ).

WIN55,212-2 on behavior and physiology were mostly mediated by CB1r.

However, the blocking effect of AM251 was not observed when extinction was tested. WIN55,212-2 is a nonselective cannabinoid agonist that activates CB1r, CB2r, TRPV1, and so on (Breivogel et al, 2001; Pertwee et al, 2010). Specifically, CB2r was found to be involved in the consolidation of fear memory (García-Gutiérrez et al, 2013), which might explain why the CB1 antagonist AM251 administered after the conditioned shock did not block the effects of WIN55,212-2 on extinction.

We have previously found that AM251 blocked the effects of WIN55,212-2 on inhibitory avoidance and contextual extinction (Ganon-Elazar and Akirav, 2012, 2013). However, here we measured the extinction of the traumatic event itself, and not the extinction of conditioned fear that is not directly associated with the traumatic event (Ganon-Elazar and Akirav, 2012, 2013).

\section{Avoidance and Extinction}

Shocked rats exposed to SRs persistently avoided the dark chamber, although they were repeatedly exposed to this chamber under safe conditions (that is, with no shock exposure). Interestingly, shocked rats not exposed to SRs demonstrated increased avoidance on the first extinction trial, but their extinction kinetics was intact. Pamplona et al (2011) examined the emergence of avoidance behavior in the aftermath of a trauma in mice and found that fear incubation after a highly aversive experience induces timedependent quantitative and qualitative change in avoidance behavior, mirroring fear incubation in human PTSD. Specific conditioned avoidance to shock-paired odor occurred shortly after trauma (2 days) and turned into generalized avoidance after 28 days of fear incubation. They suggested that generalized avoidance results from a mixture of both sensitized and conditioned fear responses and that generalized avoidance reduced through both habituation to the test environment (that is, safety learning) and post-incubation extinction of contextual fear (Pamplona et al, 2011). In our study, 1 week after the shock, extinction training reduced avoidance in rats exposed to shock with no SRs, whereas shock-SR rats continued to avoid the dark chamber.

The relationship between fear extinction deficits and avoidance symptoms in PTSD might be bidirectional. Previous studies suggest that extinction deficits can lead to the development of avoidance symptoms, and conversely that pre-existent 'higher avoidance' can be a contributor to extinction deficits. In support of the first hypothesis, greater fear in response to aversive stimuli was associated with greater levels of subsequent avoidance in rats (Chen et al, 2012) and pre-trauma deficits in extinction learning were associated with greater risk for developing PTSD after trauma in humans (Lommen et al, 2013).

In contrast to previous studies in rats and humans in which the deficits in extinction were to a fear-conditioning paradigm not directly associated with the initial trauma (Milad et al, 2007, 2008; Ganon-Elazar and Akirav, 2012, 

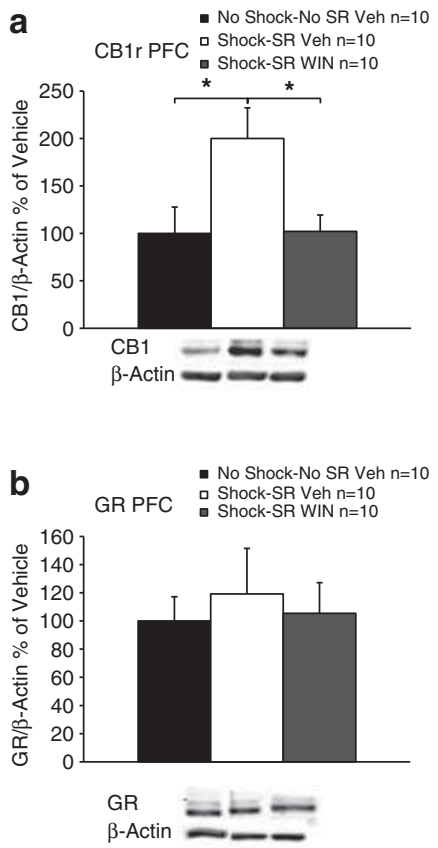

C

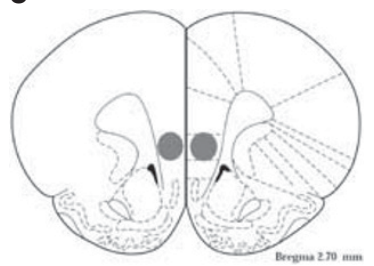

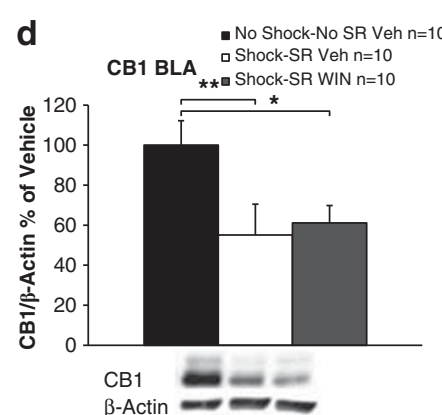

$\beta$-Actin $=-$

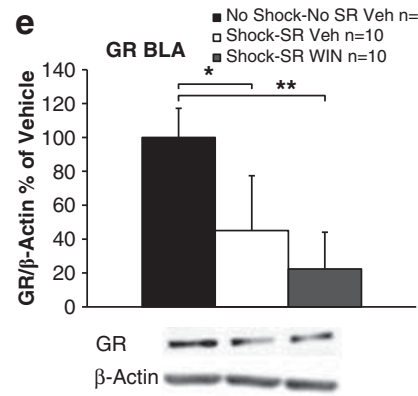

$\mathbf{f}$

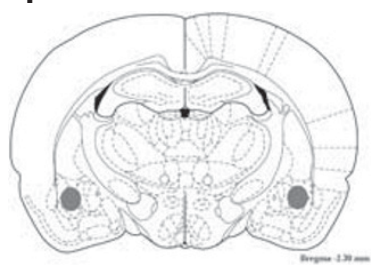

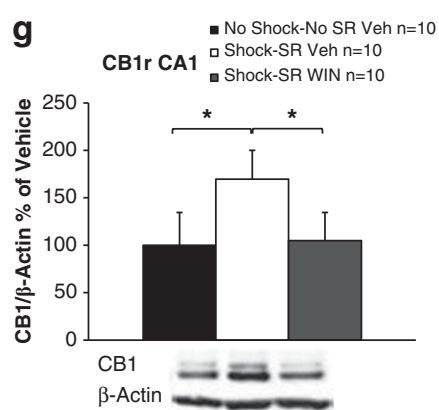
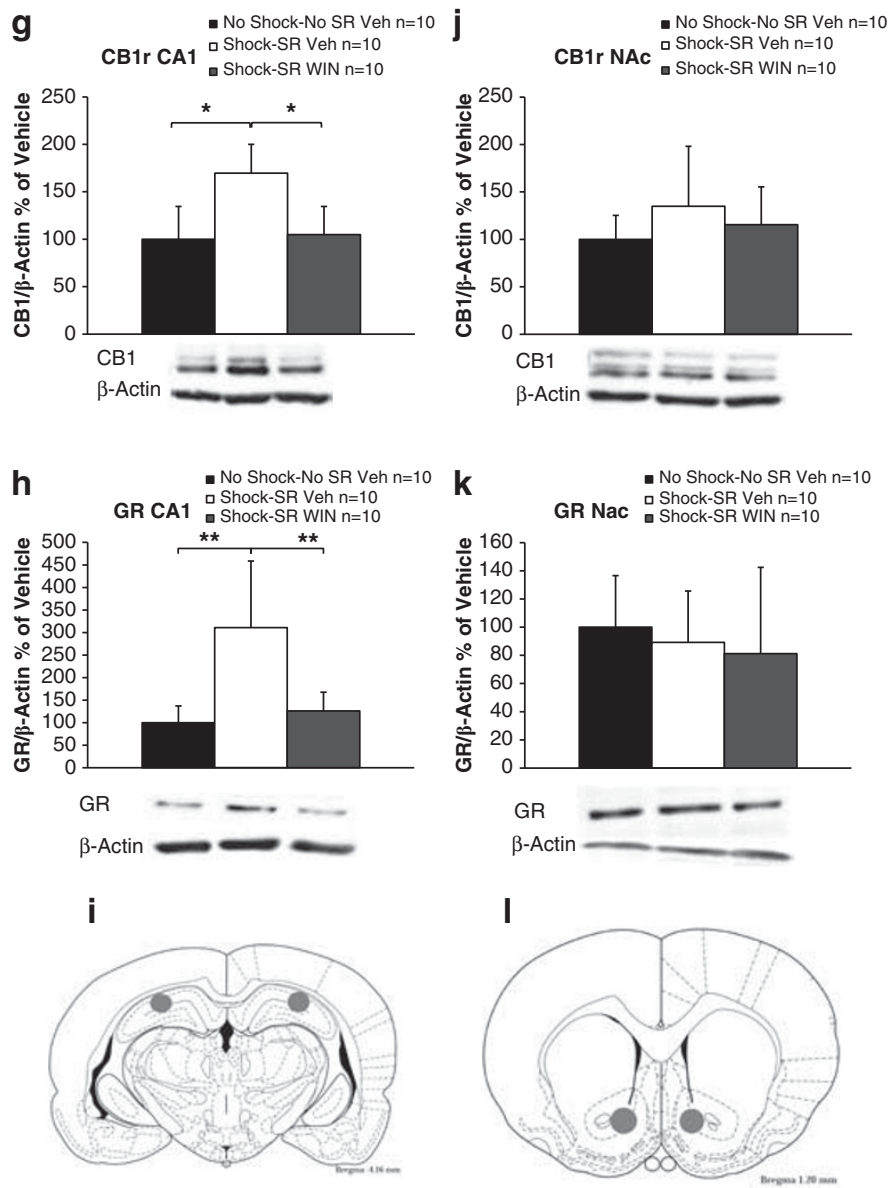

Figure $4 \mathrm{CB}$ I receptor and GR expression in the fear circuit. Representative bands for the expression of GR/CBIr and $\beta$-actin (lower panel). (a) In the IL-PFC, the shock-SR Veh group expressed significantly more CBIr compared with all groups $(* p<0.05)$. (b) In the IL-PFC, no significant difference was observed in GRs between the groups. (c) Brain sites from where the tissue samples were extracted. The IL-PFC was obtained by punches (I mm diameter) bilaterally. The numbers refer to the distance from Bregma (based on Paxinos and Watson, 1996). (d) In the BLA, the no shock-no SR Veh group expressed more CBIr compared with all groups ( $p<0.05$; *** $<0.01$ ). (e) In the BLA, the no shock-no SR Veh group expressed more GRs compared with all groups $(* p<0.05$; ** $p<0.0 \mathrm{I})$. ( $\mathrm{f}$ ) The BLA was obtained by punches (I mm diameter) bilaterally. ( $\mathrm{g}$ ) In the CAI, the shock-SR Veh group expressed significantly more CBIr compared with all groups $(* p<0.05)$. (h) In the CAI, the shock-SR Veh group expressed more GR compared with all groups $(* * * 2<0.0 \mathrm{I}$ ). (i) The CAI was obtained by punches (I mm diameter) bilaterally. (j) In the NAc, no significant effect was found for CBIr. ( $k$ ) In the NAc, no significant effect was found for GR. (I) The NAc was obtained by punches ( I mm diameter) bilaterally.

2013; Sripada et al, 2013), here extinction training was directed at extinguishing the traumatic event. This is important as abnormalities in extinction may be particularly salient for the persistence of fear memories in PTSD (Milad et al, 2008).

We found that exposure to SRs exacerbated the effects of the shock. To further validate the model, we added a control experiment in which rats were exposed to shock on day 1 , and then exposed to a stressor on days 3 and 5 (30 min on the EP). Rats exposed to shock and EP (with no SRs) demonstrated increased latency to enter the dark side and reduced latency to startle compared with rats exposed to shock and SRs. Hence, exposure to repeated stress did not exacerbate the effects of the shock as seen with SR exposure. This suggests that the effects of exposure on SRs could not be mimicked by repeated out-of-context stress.

We also added a control experiment in which a 'classical' PTSD drug (that is, sertraline) was injected acutely $2 \mathrm{~h}$ after the shock (similar to the WIN55,212-2 experiment) or for once daily for 7 days. We found that the acute treatment had no effect on extinction and that the 1-week treatment facilitated extinction compared with a vehicle-treated group. This corroborates with a previous study demonstrating that administration of sertraline for 7 days immediately post stress exposure (that is, predator scent stress) reduced anxiety-like and avoidant behavior compared with the saline controls (Matar et al, 2006). This further validates the trauma and reminders' model as a PTSD model. Nonetheless, the effects of sertraline, even when administered for 7 days, were not as robust as the effects of WIN55,212-2 on extinction in our model (the sertraline-treated rats showed reduced latency on the third and fourth extinction days).

\section{Plasticity}

Shock-SR rats showed impaired NAc LTP 1 week after shock exposure and the agonist WIN55,212-2 prevented this impairment. Recently, we found that exposure to 3 weeks of chronic mild stress impaired NAc LTP tested $48 \mathrm{~h}$, but not 1 week after the stressor ended (Segev et al, 2013). Gill and 
Grace (2013) demonstrated that following repeated restraint, but not after acute restraint, HFS of the vSub failed to potentiate the vSub-NAc pathway. Hence, it seems that the joint effects of the shock and SRs were significant enough to result in a lasting impairment effect on NAc LTP.

Together with data from the literature, our results suggest that the NAc is embedded within the brain circuit that regulates fear (Schwienbacher et al, 2004; Muschamp et al, 2011). It has been shown that inactivating the NAc blocked conditioned fear (Schwienbacher et al, 2004) and that CREB activation within the NAc produced multiple behavioral signs (anhedonia, impaired extinction) characteristic of experience-dependent psychiatric conditions such as depression and PTSD (Muschamp et al, 2011).

\section{Startle Response}

Exposure to shock and SRs, but not shock alone, enhanced the latency to startle, suggesting that exposure to SRs exacerbated the effects of the trauma. It is notable that the agonist WIN55,212-2 prevented this shock/SR-induced enhancement because abnormal startle response is a noninvasive translational tool of research that bridges the gap between animal and human investigations and it is a recognized symptom of human PTSD (Grillon and Baas, 2003).

However, evidence is conflicting regarding the question whether the auditory startle reflex is in fact increased in patients with PTSD and other anxiety disorders (Grillon and Baas, 2003). Some studies have shown increased startle responses in PTSD (Grillon et al, 1998; Holstein et al, 2010), whereas other studies found no difference (Lipschitz et al, 2005; Jovanovic et al, 2009), or even smaller responses (Ornitz and Pynoos, 1989). Also there are no consistent findings on habituation (Grillon et al, 1996; Metzger et al, 1999). As far as the increased latency of the startle response, there is evidence that PTSD patients show increased latency to startle (Vrana et al, 2013).

\section{Sensory-Motor Tests and Unconditioned Anxiety}

In the OF test, shocked rats (with or without SR exposure) demonstrated decreased locomotion, increased freezing, and a decrease in time spent in the center of the OF, indicating enhanced anxiety 1 week after exposure to an intense shock. The agonist WIN55,212-2 did not prevent the shock-induced anxiety, corroborating with a previous study demonstrating that WIN55,212-2 can prevent PTSD-like symptoms (such as enhanced startle response, impaired extinction, and alterations in the HPA axis), but it has no effect on unconditioned anxiety levels (Ganon-Elazar and Akirav, 2012). This suggests that the effects of WIN55,212-2 in preventing PTSD-like symptoms are not due to a general 'relaxation effect' or to an erasure of the stressful event, as rats injected with WIN55,212-2 after the shock still exhibit increased unconditioned anxiety (Ganon-Elazar and Akirav, 2012).

In the EPM, shocked rats also demonstrated decreased locomotion but surprisingly spent more time in the open arms, which usually suggests less anxiety. A possible explanation to this puzzling effect is that shocked rats generalized from the dark chamber where they received the shock to the dark arms of the EPM, hence resulting in spending more time in the 'safe' open arms. In support, we found that shocked animals demonstrated increased freezing in the open arms compared with nonshocked rats (data not shown). Hence, they stayed in the open arms for longer duration. This generalization effect was observed in other studies as well. Olson et al (2011) demonstrated that mice exposed to shock and SRs that were tested in the light-dark test as a second measure of fear response spent less time in the dark chamber than control mice.

In the PS test, shocked rats (with or without SRs) were less sensitive to shock intensity, suggesting an effect that was specifically associated with the shock. Assessment of PS in PTSD patients suggests that PTSD can be associated with both increases and decreases in experimental PS (Asmundson and Katz, 2009; Moeller-Bertram et al, 2012). Hypoalgesia was observed in other animal models for PTSD such as SPS (Imanaka et al, 2006; Takahashi et al, 2006). In human studies, PTSD veterans demonstrated a $30 \%$ decrease in reported pain intensity ratings of standardized heat stimuli after the combat videotape suggesting hypoalgesia in response to combat-related cues (Pitman et al, 1990).

\section{CB1r and GRs}

Fear-conditioning experiments have delineated an amygdalahippocampal-cortico-striatal circuit as a key brain circuit responsible for processing and storing fear-related memories and for coordinating fear-related behaviors (Neumeister et al, 2013).

Shock and SR exposure upregulated CB1r in the PFC and CA1, and WIN55,212-2 normalized this effect. Our data are consistent with other studies showing that CB1r expression is sensitive to stressful experiences, as animals submitted to a fear-conditioning paradigm presented CB1r upregulation in the PFC (Lisboa et al, 2010). Campos et al (2012) on the other hand have shown that 7 days after a single predator exposure, CB1 mRNA expression was downregulated in the frontal cortex. This discrepancy may result from the different stress paradigms that were used. CB1r are also modulated in the hippocampus by chronic stress; a significant reduction in $\mathrm{CB} 1$ receptor binding in the dentate gyrus with a parallel increase in the CA3 region was observed (Hill et al, 2009).

Shock and SR exposure also upregulated GRs in the CA1 and WIN55,212-2 prevented this effect. We have previously shown that exposure to the SPS model of PTSD upregulated GRs in the CA1, BLA, and PFC, and WIN55,212-2 administered $2 \mathrm{~h}$ after SPS exposure prevented the CA1 and BLA upregulation (Ganon-Elazar and Akirav, 2013). The differences may stem from the different stress paradigm used; the SPS paradigm involves $2 \mathrm{~h}$ of restraint followed by forced swim and sedation, and then the animals are left undisturbed for 1 week. In the current paradigm, an intensive footshock is applied, followed by SRs that exacerbate the negative effects of the shock.

In the BLA, shock and SR exposure downregulated CB1r and GRs, and WIN55,212-2 did not normalize this effect. It is possible that exposure to an intense shock caused immediate changes in the BLA, such as increased release of endocannabinoids and glucocorticoids that may result in lasting downregulation of $\mathrm{CB} 1 \mathrm{r}$ and GRs in this brain area. In support, 
it has been shown that glucocorticoids released during stress lead to an increase in endocannabinoids in the amygdala (Hill et al, 2005) and that exposure to shock or tone that was associated with shock increased endocannabinoid release in the amygdala (Marsicano et al, 2002; Morena et al, 2012). It should be noted that WIN55,212-2 did not normalize the unconditioned anxiety observed in the OF test, suggesting that these effects are mediated by the BLA.

In the NAc, no alterations in CB1r or GRs were observed. The NAc integrates limbic and cortical inputs arising from monosynaptic glutamatergic projections that originate in the vSub, BLA, and PFC (O'Donnell and Grace, 1995; French and Totterdell, 2003). Each of these regions is believed to supply a different mode of input to the NAc, with the BLA involved in affective responses, the vSub in context dependency, and the medial PFC in behavioral flexibility.

Studies reported a low level or even lack of CB1r in the NAc, whereas other brain regions, such as the PFC, the hippocampus, and the amygdala, which densely innervate the NAc, show moderate to very high CB1r levels (Tsou et al, 1997). Nevertheless, it has been argued that CB1expressing neurons in the NAc, although sparse, appear to be critical for emotional and motivational responses. Specifically, it has been suggested that manipulation of CB1 signaling within the NAc triggers robust emotional/ motivational alterations related to drug addiction and other psychiatric disorders, and that these effects cannot be exclusively attributed to CB1 located at afferents to the NAc (Winters et al, 2012). Taken together, this might explain why we have robust effects on plasticity in the vSub-NAc pathway, but not on the expression of CB1r in this area.

A similar picture emerges with GRs; GRs are highly expressed in the CA1 and moderately expressed in the BLA and PFC, whereas the NAc shell expresses low density (Ahima and Harlan, 1990). It has been suggested that the BLA, hippocampus, and PFC are likely candidates for conveying the indirect effects of cannabinoids on dopamine release within the NAc, thereby contributing to reward processes (Katona et al, 2001).

Studies indicate a bidirectional, functional relationship between glucocorticoids and the endocannabinoid system (for review, see Akirav, 2013) and this interaction can modulate memory consolidation of emotionally arousing experiences (Campolongo et al, 2009; Hill and McEwen, 2009; Ganon-Elazar and Akirav, 2009, 2013; Atsak et al, 2012; de Oliveira Alvares et al, 2010; de Bitencourt et al, 2013; Segev et al, 2013).

Stress and glucocorticoids can trigger endocannabinoid synthesis to constrain HPA axis activity under acute conditions in the brain's fear circuit (that is, BLA, hippocampus, and medial PFC) (Marsicano et al, 2002; Rademacher et al, 2008; de Oliveira Alvares et al, 2010; Hill et al, 2011; Wang et al, 2011). In the hippocampus and PFC, the recruitment of endocannabinoids by glucocorticoids likely increases the outflow of the principal neurons of these regions to contribute to termination of the stress response (de Oliveira Alvares et al, 2010; Hill et al, 2011). In the BLA, the endocannabinoids bind to presynaptic CB1r on GABAergic terminals, which rapidly suppress the release of GABA. One model suggests that inhibition of GABA release disinhibits norepinephrine release and increases norepinephrine activation of postsynaptic $\beta$-adrenoreceptors, increasing the consolidation of emotionally aversive memories (Campolongo et al, 2009; Hill and McEwen, 2009; Atsak et al, 2012). Another model suggests that inhibition of GABA release in BLA interneurons reduces their inhibition of the GABAergic neurons of the intercalated nuclei, which, in turn, increases their inhibition of the pyramidal neurons of the central amygdala (Katona et al, 2001). The end result of the reduction in inhibitory tone may be reduced HPA axis activity and attenuation of the effects of stress on memory (Katona et al, 2001; Akirav, 2013).

Taken together, it can be suggested that in our study, endocannabinoids release was not sufficient to constrain HPA axis activity after exposure to shock and SRs, and administering WIN55,212-2 compensated for this reduced constrain and prevented the effects of shock and SRs on extinction, startle, and plasticity via CB1r in the PFC, and CB1r and GRs in the CA1. In previous studies, we found that intra-BLA WIN55,212-2 prevented the effects of stress on emotional memory (Ganon-Elazar and Akirav, 2009, 2012); however, in this study, WIN55,212-2 was injected systemically and this probably results in a different effect on emotional processing than a specific intra-BLA injection. Another explanation is that the effects of an intense shock on amygdala processing are different than the effects of exposure to other stressors that are not associated with shock or fear (that is, the SPS model). In support, it has been shown that restraint stress decreased (Hill et al, 2009), whereas shock or tone associated with the shock increased (Marsicano et al, 2002; Morena et al, 2012) anandamide levels in the amygdala.

In conclusion, shock and SR exposure in rats caused lasting alterations in emotional processing associated with changes in GR and $\mathrm{CB} 1 \mathrm{r}$ expression in brain areas dysfunctional in PTSD. WIN55,212-2 administered after trauma exposure prevented these alterations via CB1r in the PFC, and CA1 and GRs in the CA1. This suggests that the connectivity in the fear circuit is altered following trauma and CB1r activation and thus may result in lasting effects on emotional processing.

\section{FUNDING AND DISCLOSURE}

The authors declare no conflict of interest.

\section{ACKNOWLEDGEMENTS}

This research was supported by THE ISRAEL SCIENCE FOUNDATION (grant no. 572/12 to IA; URL:http://www. isf.org.il/).

\section{REFERENCES}

Abush H, Akirav I (2010). Cannabinoids modulate hippocampal memory and plasticity. Hippocampus 20: 1126-1138.

Abush H, Akirav I (2013). Cannabinoids ameliorate impairments induced by chronic stress to synaptic plasticity and short-term memory. Neuropsychopharmacology 38: 1521-1534.

Ahima RS, Harlan RE (1990). Charting of type II glucocorticoid receptor-like immunoreactivity in the rat central nervous system. Neuroscience 39: 579-604. 
Akirav I (2013). Cannabinoids and glucocorticoids modulate emotional memory after stress. Neurosci Biobehav Rev 37: 2554-2563.

Asmundson GJ, Katz J (2009). Understanding the co-occurrence of anxiety disorders and chronic pain: state-of-the-art. Depress Anxiety 26: 888-901.

Atsak P, Roozendaal B, Campolongo P (2012). Role of the endocannabinoid system in regulating glucocorticoid effects on memory for emotional experiences. Neuroscience 204: 104-116.

de Bitencourt RM, Pamplona FA, Takahashi RN (2013). A current overview of cannabinoids and glucocorticoids in facilitating extinction of aversive memories: potential extinction enhancers. Neuropharmacology 64: 389-395.

Breivogel CS, Griffin G, Di Marzo V, Martin BR (2001). Evidence for a new $G$ protein-coupled cannabinoid receptor in mouse brain. Mol Pharmacol 60: 155-163.

Campolongo P, Roozendaal B, Trezza V, Hauer D, Schelling G, McGaugh JL et al (2009). Endocannabinoids in the rat basolateral amygdala enhance memory consolidation and enable glucocorticoid modulation of memory. Proc Natl Acad Sci USA 106: $4888-4893$.

Campos AC, Ferreira FR, da Silva WA, Guimarães FS (2012). Predator threat stress promotes long lasting anxiety-like behaviors and modulates synaptophysin and $\mathrm{CB} 1$ receptors expression in brain areas associated with PTSD symptoms. Neurosci Lett 533: 34-38.

Chen X, Li Y, Li S, Kirouac GJ (2012). Early fear as a predictor of avoidance in a rat model of post-traumatic stress disorder. Behav Brain Res 226: 112-117.

Corral-Frias NS, Lahood RP, Edelman-Vogelsang KE, French ED, Fellous J-M (2013). Involvement of the ventral tegmental area in a rodent model of post-traumatic stress disorder. Neuropsychopharmacology 38: 350-363.

Fraser GA (2009). The use of a synthetic cannabinoid in the management of treatment-Resistant nightmares in posttraumatic stress disorder (PTSD). CNS Neurosci Ther 15: 84-88.

French SJ, Totterdell S (2003). Individual nucleus accumbensprojection neurons receive both basolateral amygdala and ventral subicular afferents in rats. Neuroscience 119: 19-31.

Ganon-Elazar E, Akirav I (2009). Cannabinoid receptor activation in the basolateral amygdala blocks the effects of stress on the conditioning and extinction of inhibitory avoidance. J Neurosci 29: 11078

Ganon-Elazar E, Akirav I (2012). Cannabinoids prevent the development of behavioral and endocrine alterations in a rat model of intense stress. Neuropsychopharmacology 37: 456-466.

Ganon-Elazar E, Akirav I (2013). Cannabinoids and traumatic stress modulation of contextual fear extinction and GR expression in the amygdala-hippocampal-prefrontal circuit. Psychoneuroendocrinology 38: 1675-1687.

García-Gutiérrez MS, Ortega-Álvaro A, Busquets-García A, PérezOrtiz JM, Caltana L, Ricatti MJ et al (2013). Synaptic plasticity alterations associated with memory impairment induced by deletion of CB2 cannabinoid receptors. Neuropharmacology 73: 388-396.

Gill KM, Grace AA (2013). Differential effects of acute and repeated stress on hippocampus and amygdala inputs to the nucleus accumbens shell. Int J Neuropsychopharmacol 16: 2013-2025.

Grillon C, Baas J (2003). A review of the modulation of the startle reflex by affective states and its application in psychiatry. Clin Neurophysiol 114: 1557-1579.

Grillon C, Dierker L, Merikangas KR (1998). Fear-potentiated startle in adolescent offspring of parents with anxiety disordersf. Biol Psychiatry 44: 990-997.

Grillon C, Morgan CA, Southwick SM, Davis M, Charney DS (1996). Baseline startle amplitude and prepulse inhibition in Vietnam veterans with posttraumatic stress disorder. Psychiatry Res 64: 169-178.
Heim C, Nemeroff CB (2009). Neurobiology of posttraumatic stress disorder. CNS Spectr 14: 13-24.

Hill MN, Ho W-SV, Meier SE, Gorzalka BB, Hillard CJ (2005). Chronic corticosterone treatment increases the endocannabinoid 2-arachidonylglycerol in the rat amygdala. Eur J Pharmacol 528: 99-102.

Hill MN, McEwen BS (2009). Endocannabinoids: the silent partner of glucocorticoids in the synapse. Proc Natl Acad Sci USA 106: 4579-4580.

Hill MN, McLaughlin RJ, Morrish AC, Viau V, Floresco SB, Hillard CJ et al (2009). Suppression of amygdalar endocannabinoid signaling by stress contributes to activation of the hypothalamic-pituitaryadrenal axis. Neuropsychopharmacology 34: 2733-2745.

Hill MN, McLaughlin RJ, Pan B, Fitzgerald ML, Roberts CJ, TT-Y Lee et al (2011). Recruitment of prefrontal cortical endocannabinoid signaling by glucocorticoids contributes to termination of the stress response. J Neurosci 31: 10506-10515.

Holstein DH, Vollenweider FX, Jäncke L, Schopper C, Csomor PA (2010). P50 suppression, prepulse inhibition, and startle reactivity in the same patient cohort suffering from posttraumatic stress disorder. J Affect Disord 126: 188-197.

Imanaka A, Morinobu S, Toki S, Yamawaki S (2006). Importance of early environment in the development of post-traumatic stress disorder-like behaviors. Behav Brain Res 173: 129-137.

Jovanovic T, Norrholm SD, Sakoman AJ, Esterajher S, KozarićKovačić D (2009). Altered resting psychophysiology and startle response in Croatian combat veterans with PTSD. Int $J$ Psychophysiol 71: 264-268.

Katona I, Rancz EA, Acsády L, Ledent C, Mackie K, Hájos N et al (2001). Distribution of CB1 cannabinoid receptors in the amygdala and their role in the control of GABAergic transmission. J Neurosci 21: 9506-9518.

Kogan NM, Mechoulam R (2006). The chemistry of endocannabinoids. J Endocrinol Invest 29: 3.

Lipschitz DS, Mayes LM, Rasmusson AM, Anyan W, Billingslea E, Gueorguieva R et al (2005). Baseline and modulated acoustic startle responses in adolescent girls with posttraumatic stress disorder. J Am Acad Child Adolesc Psychiatry 44: 807-814.

Lisboa SF, Reis DG, da Silva AL, Corrêa F, Guimaraes FS, Resstel L (2010). Cannabinoid CB1 receptors in the medial prefrontal cortex modulate the expression of contextual fear conditioning. Int J Neuropsychopharmacol 13: 1163-1173.

Lommen MJ, Engelhard IM, Sijbrandij M, van den Hout MA, Hermans D (2013). Pre-trauma individual differences in extinction learning predict posttraumatic stress. Behav Res Ther 51: 63-67.

Louvart H, Maccari S, Ducrocq F, Thomas P, Darnaudéry M (2005). Long-term behavioural alterations in female rats after a single intense footshock followed by situational reminders. Psychoneuroendocrinology 30: 316-324.

Maroun M, Akirav I (2008). Arousal and stress effects on consolidation and reconsolidation of recognition memory. Neuropsychopharmacology 33: 394-405.

Marsicano G, Wotjak CT, Azad SC, Bisogno T, Rammes G, Cascio MG et al (2002). The endogenous cannabinoid system controls extinction of aversive memories. Nature 418: 530-534.

Matar MA, Cohen H, Kaplan Z, Zohar J (2006). The effect of early poststressor intervention with sertraline on behavioral responses in an animal model of post-traumatic stress disorder. Neuropsychopharmacology 31: 2610-2618.

Metzger LJ, Orr SP, Berry NJ, Ahern CE, Lasko NB, Pitman RK (1999). Physiologic reactivity to startling tones in women with posttraumatic stress disorder. J Abnorm Psychol 108: 347.

Milad MR, Orr SP, Lasko NB, Chang Y, Rauch SL, Pitman RK (2008). Presence and acquired origin of reduced recall for fear extinction in PTSD: results of a twin study. $J$ Psychiatr Res 42: $515-520$ 
Milad MR, Quirk GJ (2002). Neurons in medial prefrontal cortex signal memory for fear extinction. Nature 420: 70-74.

Milad MR, Wright CI, Orr SP, Pitman RK, Quirk GJ, Rauch SL (2007). Recall of fear extinction in humans activates the ventromedial prefrontal cortex and hippocampus in concert. Biol Psychiatry 62: 446-454.

Moeller-Bertram T, Keltner J, Strigo IA (2012). Pain and post traumatic stress disorder-review of clinical and experimental evidence. Neuropharmacology 62: 586-597.

Moreira FA, Wotjak CT (2010). Cannabinoids and anxiety. Curr Top Behav Neurosci 2: 429-450.

Morena M, Hauer D, Ratano P, Scaccianoce S, Trezza V, Pecci C et al (2012). The endo-cannabinoid system and the regulation of memory consolidation for emotionally arousing experiences. FENS Abstract 6: $\mathrm{p}$ 0.45.14.

Mueller D, Porter JT, Quirk GJ (2008). Noradrenergic signaling in infralimbic cortex increases cell excitability and strengthens memory for fear extinction. J Neurosci 28: 369-375.

Muschamp JW, Van't Veer A, Parsegian A, Gallo MS, Chen M, Neve RL et al (2011). Activation of CREB in the nucleus accumbens shell produces anhedonia and resistance to extinction of fear in rats. J Neurosci 31: 3095-3103.

Nathan PJ, Cobb SR, Lu B, Bullmore ET, Davies CH (2011). Studying synaptic plasticity in the human brain and opportunities for drug discovery. Curr Opin Pharmacol 11: 540-548.

Nestler EJ, Carlezon WA (2006). The mesolimbic dopamine reward circuit in depression. Biol Psychiatry 59: 1151-1159.

Neumeister A, Normandin MD, Pietrzak RH, Piomelli D, Zheng MQ, Gujarro-Anton A et al (2013). Elevated brain cannabinoid CB1 receptor availability in post-traumatic stress disorder: a positron emission tomography study. Mol Psychiatry 18: 1034-1040.

O’Donnell P, Grace AA (1995). Synaptic interactions among excitatory afferents to nucleus accumbens neurons: hippocampal gating of prefrontal cortical input. J Neurosci 15: 3622-3639.

de Oliveira Alvares L, Engelke DS, Diehl F, Scheffer-Teixeira R, Haubrich J, de Oliveira Alvares L et al (2010). Stress response recruits the hippocampal endocannabinoid system for the modulation of fear memory. Learn Mem 17: 202-209.

Olson VG, Rockett HR, Reh RK, Redila VA, Tran PM, Venkov HA et al (2011). The role of norepinephrine in differential response to stress in an animal model of posttraumatic stress disorder. Biol Psychiatry 70: 441-448.

Ornitz EM, Pynoos RS (1989). Startle modulation in children with posttraumatic stress disorder. Am J Psychiatry 146: 866-870.

Pamplona FA, Henes K, Micale V, Mauch CP, Takahashi RN, Wotjak CT (2011). Prolonged fear incubation leads to generalized avoidance behavior in mice. J Psychiatr Res 45: 354-360.

Paxinos G, Watson C (1996). The Rat Brain in Stereotaxic Coordinates. Academic Press: San Diego, CA.

Pertwee RG, Howlett AC, Abood ME, Alexander SPH, Di Marzo V, Elphick MR et al (2010). International Union of Basic and
Clinical Pharmacology. LXXIX. Cannabinoid receptors and their ligands: beyond CB1 and CB2. Pharmacol Rev 62: 588-631.

Pitman RK, Van der Kolk BA, Orr SP, Greenberg MS (1990). Naloxone-reversible analgesic response to combat-related stimuli in posttraumatic stress disorder: a pilot study. Arch Gen Psychiatry 47: 541-544.

Pynoos RS, Ritzmann RF, Steinberg AM, Goenjian A, Prisecaru I (1996). A behavioral animal model of posttraumatic stress disorder featuring repeated exposure to situational reminders. Biol Psychiatry 39: 129-134.

Rademacher DJ, Meier SE, Shi L, Vanessa Ho W-S, Jarrahian A, Hillard CJ (2008). Effects of acute and repeated restraint stress on endocannabinoid content in the amygdala, ventral striatum, and medial prefrontal cortex in mice. Neuropharmacology 54: 108-116.

Schwienbacher I, Fendt M, Richardson R, Schnitzler H-U (2004). Temporary inactivation of the nucleus accumbens disrupts acquisition and expression of fear-potentiated startle in rats. Brain Res 1027: 87-93.

Segev A, Rubin AS, Abush H, Richter-Levin G, Akirav I (2013). Cannabinoid receptor activation prevents the effects of chronic mild stress on emotional learning and LTP in a rat model of depression. Neuropsychopharmacology 39: 919-933.

Sripada RK, Garfinkel SN, Liberzon I (2013). Avoidant symptoms in PTSD predict fear circuit activation during multimodal fear extinction. Front Hum Neurosci 7: 672.

Stein DJ, Ipser JC, Seedat S (2006). Pharmacotherapy for post traumatic stress disorder (PTSD). Cochrane Database Syst Rev 1: CD002795.

Takahashi T, Morinobu S, Iwamoto Y, Yamawaki S (2006). Effect of paroxetine on enhanced contextual fear induced by single prolonged stress in rats. Psychopharmacology (Berl) 189: $165-173$.

Tsou K, Brown S, Sanudo-Pena MC, Mackie K, Walker JM (1997). Immunohistochemical distribution of cannabinoid CB1 receptors in the rat central nervous system. Neuroscience 83: 393-411.

Vrana SR, Calhoun PS, McClernon FJ, Dennis MF, Lee ST, Beckham JC (2013). Effects of smoking on the acoustic startle response and prepulse inhibition in smokers with and without posttraumatic stress disorder. Psychopharmacology (Berl) 230: 477-485.

Wang M, Hill MN, Zhang L, Gorzalka BB, Hillard CJ, Alger BE (2011). Acute restraint stress enhances hippocampal endocannabinoid function via glucocorticoid receptor activation. J Psychopharmacol 26: 56-70.

Winters BD, Krüger JM, Huang X, Gallaher ZR, Ishikawa M, Czaja K et al (2012). Cannabinoid receptor 1-expressing neurons in the nucleus accumbens. Proc Natl Acad Sci USA 109: E2717-E2725.

Yehuda R, Flory JD, Southwick S, Charney DS (2006). Developing an agenda for translational studies of resilience and vulnerability following trauma exposure. Ann NY Acad Sci 1071: 379-396.

Zohar J, Juven-Wetzler A, Sonnino R, Cwikel-Hamzany S, Balaban E, Cohen H (2011). New insights into secondary prevention in posttraumatic stress disorder. Dialogues Clin Neurosci 13: 301. 